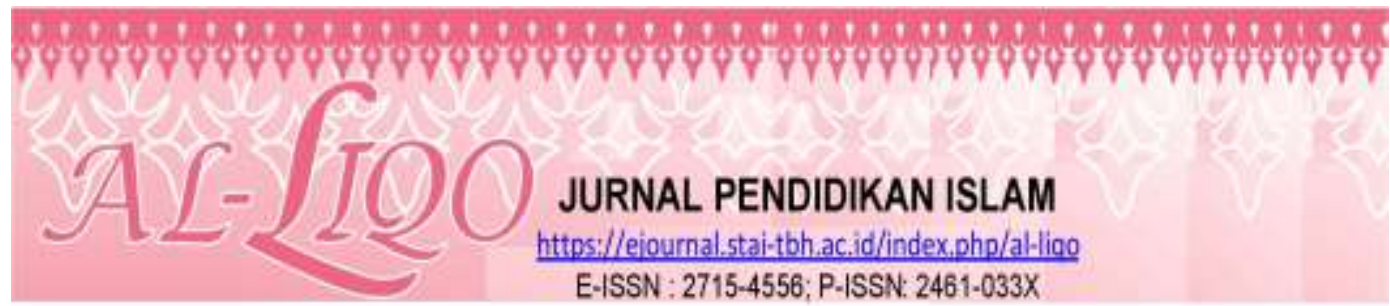

\title{
PEMIKIRAN SYEKH ABDUL QADIR AL-JAILANI TENTANG MA'RIFAT
}

\author{
Kafrawi ${ }^{1)}$ \\ ${ }^{1}$ Dosen Tetap Program Studi Pendidikan Agama Islam STAI Auliaurrasyidin Tembilahan \\ Kabupaten Indragiri Hilir Propinsi Riau. Email : kafrawi@stai-tbh.ac.id
}

\begin{abstract}
Abstrak
Syekh Abdul Qadir Al-Jailani adalah putra dari Abu Sholeh bin Musa bin Abdullah bin Yahya Al-Yazid bin Muhammad bin daud bin musa al-juwainy bin Abdullah al-Makhdli bin Hasan Al-Mutsanna bin Hasan bin Ali bin Abi Thalib ra dan Ibunya bernama Syarifah Fatimah binti Abdullah Al-Shoma'I bin Abu Jamaluddin bin Mahmud bin Thohir bin Abu Atho Abdillah bin Kamaluddin Isa bin Alauddin Muhammad Al-Jawwad bin Ali Al-Ridha bin Musa Kadzim bin Ja'far As-Shadiq bin Muhammad Al-Baqir bin Zainal Abiding bin Husain Al-Syahid binti Fatimah ra binti Rasulullah SAW. Ma'rifah adalah ketetapan hati dalam mempercayai hadirnya wujud yang wajib adanya Allah SWT yang menggambarkan segala kesempurnaannya. Ma'rifat terhadap dzat Allah SWT adalah mengetahui bahwa sesungguhnya Allah adalah wujud Esa, Tunggal dan sesuatu Yang Maha Agung, mandiri dengan sendiri-Nya dan tidak ada sesuatu pun yang menyamai-Nya. Sedangkan ma'rifat terhadap sifat Allah SWT adalah mengetahui dengan sesungguhnya bahwa Allah Maha hidup, Maha mengetahui, Maha kuasa, Maha mendengar, Maha melihat dengan segala sifat keparipurnaan-Nya. Dan akan tampak dalam hidupnya kalbu bersama Allah SWT. Rumusan masalah yaitu; Siap saja Guru-guru Syekh Abdul Qadir Al-Jailani, apa saja karya Syekh Abdul Qadir Al-Jailani, Gambaran ma'rifah secara umum serta, maqam untuk mencapai ma'rifah, konsep ma'rifat Syeikh Abdul Qadir Al-Jailani.
\end{abstract}

Kata Kunci : Pemikiran Syekh Abdul Qadir Al-Jailani, Ma'rifat

\section{PENDAHULUAN}

Pendidikan merupakan masalah yang sangat penting untuk terus dikembangkan, dengan pendidikan yang baik, maka suatu bangsa akan dapat tumbuh dan berkembang pesat dalam berbagai bidang kehidupan. Jadi, pendidikan merupakan kunci suatu keberhasilan. Jika dilihat dari kehidupan dunia, peradaban Islam banyak melahirkan tokoh-tokoh besar dalam berbagai bidang ilmu pengetahuan, khususnya bidang pendidikan. Sejarah dunia telah memberikan contoh-contoh mengagumkan terhadap para tokoh pendidikan yang telah berhasil mendekatkan diri kepada Allah SWT dengan jalan tasawuf. 
Tasawuf merupakan "salah satu bidang studi Islam yang memusatkan perhatian pada pembersihan aspek rohani manusia yang selanjutnya dapat menimbulkan akhlak mulia". ${ }^{2}$ Melalui studi ini seseorang dapat mengetahui tentang cara-cara melakukan pembersihan diri serta mengamalkannya secara benar, dari pengetahuan ini diharapkan ia akan tampil sebagai seorang yang pandai mengendalikan dirinya pada saat ia berinteraksi dengan orang lain, atau pada saat melakukan berbagai aktivitas dunia yang menuntut kejujuran, keikhlasan, tanggung jawab, kepercayaan dan sebagainya. Salah satu tokoh yang berhasil mendekatkan diri kepada Allah SWT sehingga mendapatkan julukan sebagai sunatul auliya adalah Syekh Abdul Qadir Al-Jailani.

Syekh Abdul Qadir Al-Jailani merupakan ulama besar yang banyak mewariskan ilmu pengetahuan. dimana, jejak hidup beliau memperlihatkan sebuah kemuliaan seorang hamba yang tidak hanya 'abid, tetapi tidak juga alim dalam tafsir, hadist, fiqih, ushul fiqh, nahwu, dan lain-lain. Syekh Abdul Qadir Al-Jailani merupakan sosok yang pada masa kecilnya selalu didatangi oleh malaikat setiap hari yang menyerupai pemuda tampan dengan tujuan untuk melindungi selama Syekh Abdul Qadir Al-Jailani masih belajar. selain itu, Syekh Abdul Qadir Al-Jailani juga bermimpi dikunjungi Rasulullah saw yang diiringi para sahabat dan imam Mujtahidin, serta para wali. Rasulullah saw bersabda kepada Abi Shalih bin musa, "wahai Abi Shalih, kamu akan diberi putra oleh Allah SWT. Putramu akan mendapat pangkat kedudukan yang tinggi di atas pangkat kewalian sebagaimana kedudukanku di atas pangkat kenabian. tak diragukan lagi, beliau lahir dan besar sebagai guru besar. Sehingga, beliau dihormati oleh ulama dan para zahid pada masanya bahkan sampai saat ini.

Sebagaimana orang pilihan Allah SWT, Syekh Abdul Qadir Al-Jailani juga memiliki pendapat yang bagus dalam masalah tauhid, sifat-ifat Allah, takdir, dan ilmu ma'rifat yang sesuai dengan sunnah. sehingga, banyak kaum muslimin yang menyanjung-nyanjungnya dan mencintainya. Sebagaimana firman Allah SWT dalam surah Yusuf ayat 111, sebagai berikut:

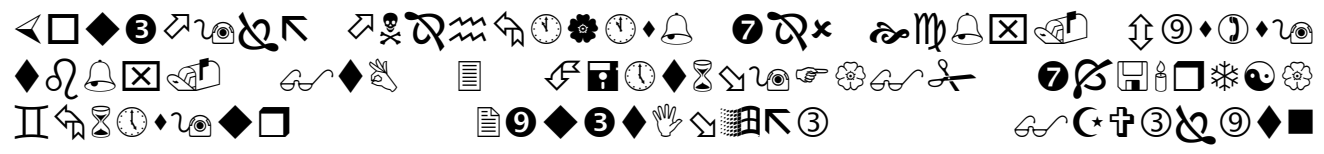

${ }^{1}$ Abudin Nata, Metodologi Studi Islam, (Jakarta:PT Raja Grafindo Persada, 2001), h. 235 


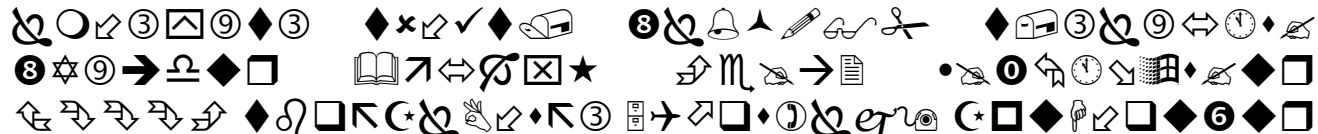
Artinya:Sesungguhnya pada kisah-kisah mereka itu terdapat pengajaran bagi orang-orang yang mempunyai akal. Al Quran itu bukanlah cerita yang dibuat-buat, akan tetapi membenarkan (kitab-kitab) yang sebelumnya dan menjelaskan segala sesuatu, dan sebagai petunjuk dan rahmat bagi kaum yang beriman.

Ayat di atas menjelaskan bahwa orang yang beriman adalah orang yang sabar dan ikhlas agar menjadi ridha bagi orang yang bertakwa. Setiap yang jujur niscaya ia berakhlak, setiap orang yang berakhlak niscaya ia beradab. Beradab artinya orang berakhlak, orang yang berakhlak niscaya orang yang berilmu. Ilmu tauhid adalah ilmu yang membahas tentang berketuhanan, sedangkan ilmu tasawuf adalah ilmu yang membahas tarikat. Hal ini mempunyai tujuan yang sama yaitu untuk mengenal Allah SWT, namun hanya jalannya saja yang berbeda. Ilmu tauhid sifat dua puluh tasawuf - tarikat - ma'rifat- penyaksian.

Syekh Abdul Qadir Al-Jailani disebut dengan sebutan sultanul auliya, yang merupakan ulama besar, kekasih Allah SWT, pemimpin para sufi, dan memiliki banyak karamah. Sehingga banyak orang yang berguru kepadanya, menimba ilmu darinya, serta gandrung dengan nasehat-nasehatnya. Sultahanul auliya yang disandangnya adalah buah keimanan dan keilmuan tertinggi pada dirinya, kehidupan yang penuh dengan makna, "ajaran-ajaran yang penuh dengan hikmah dan bagi orang yang mendengarkannya pasti akan tertarik untuk mendengarkannya lagi dan lagi". ${ }^{2}$ Hal ini yang menarik bagi penulis tentang kehidupannya hingga ia mencapai puncak kewalian, setidaknya disebabkan beberapa alasan, yaitu (a) Syekh Abdul Qadir AlJailani merupakan wali Allah SWT yang mencapai puncak kewalian, (b) perkataan Syekh Abdul Qadir Al-Jailani penuh dengan hikmah, (c) perjalanan hidupnya penuh dengan pelajaran.

Memahami fenomena di atas, peneliti tertarik untuk mengkaji lebih dalam tentang konsep ma'rifah dalam pandangan Syekh Abdul Qadir AlJailani sebagai sunatul auliya dan diharapkan dapat menambah wawasan dan

${ }^{2}$ Zainur Rofiq Ash-Shodiqy, Biografi Syekh Abdul Qadir Al-Jailani, (Jombang:Darul Hikmah, 2014), h. 3 
bekal dalam rangka memperbaiki kualitas pendidikan Indonesia pada umumnya. dan juga diharapkan dapat menjawab sebagian dari kehidupan tentang sosok Syekh Abdul Qadir Al-Jailani sebagai wali Allah SWT yang mencapai puncak kewalian.

\section{METODE PENELITIAN}

Jenis penelitian menggunakan pendekatan deskriptif kualitatif yang penulis gunakan adalah library research yaitu mengumpulkan buku-buku yang berkaitan dengan objek penelitian atau penelitian yang bersifat kepustakaan.

1. Sumber Data

Kajian yang penulis gunakan adalah penelitian perpustakaan murni, penulis akan menggunakan dua sumber, yaitu:

a. Sumber Primer

Sumber data yang berifat primer adalah buku rujukan awal dan utama dalam penelitian, sumber primer yang penulis gunakan adalah :

i. Muhammad Thom Afandi, Manaqib Syekh Abdul Qadir Al-Jailani Terjemah Al-Lujain Ad-Daani, Balong Jeruk Kunjang Kediri: Tetes Publishing, 2015)

ii. M.J. Ja'far, Wasiat Dan Nasehat Syeikh Abdul Qadir Al-Jailani, (Yogyakarta: Lafal, 2014)

iii. Muhammad Thom Afandi, Manaqib Syekh Abdul Qadir AlJailani, (Kadiri: Tetes Publishing, 2015)

iv. Syaikh Abi Danif Al-Baghadadi, Keagungan Syaikh Abdul Qadir Al-Jailani, (Jlopo-Tebel-Bareng-Jombang:Darul-Hikmah, 2009)

v. Zainur Rofiq Ash-Shodiqy, Biografi Syekh Abdul Qadir Al-Jailani, (Jombang: Darul Hikmah, 2014)

vi. Syekh Abdul Qadir Al-Jailani, Biografi Sultan Para Wali, (Jakarta: Zaman, 2015)

b. Sumber Sekunder 
Sumber sekunder adalah hasil pengumpulan yang dilakukan oleh orang lain dengan maksud tertentu dan mempunyai kategori atau klasifikasi menurut keperluan masing-masing dan kegunaan bagi peneliti masingmasing. ${ }^{3}$ Dalam hal ini Sumber data yang berifat sekunder adalah buku rujukan pendukung dalam penelitian, sumber sekunder yang penulis gunakan adalah :

i. A. Mustafa, Akhlak Tasawuf, (Bandung: Pustaka Setia, 2010)

ii. Mustafa Zahri, Kunci Memahami Ilmu Tasawuf, (Surabaya: PT Ilmu Bina, 1997)

iii. Mahjuddin, Akhlak Tasawuf 1 Mu'jizat Nabi Karamah Wali Dan Ma'rifat Sufi, (Jakarta: Kalam Mulia, 2009)

\section{Teknik Pengumpulan Data}

Teknik pengumpulan data adalah cara-cara yang digunakan oleh peneliti untuk mengumpulkan data. ${ }^{4}$ Pengumpulan data dalam penelitian ini adalah dengan cara dokumentasi. Dokumentasi adalah "ditujukan untuk memperoleh data langsung dari tempat penelitian, meliputi bukubuku yang relevan, peraturan-peraturan, laporan kegiatan, foto-foto, fim, dokumenter, data yang relevan penelitian". 5

3. Teknik Analisa Data

Teknik analisa data adalah cara penghitungan untuk menjawab rumusan masalah dan pengujian hipotesis yang diajukan. ${ }^{6}$ Hipotesis adalah jawaban sementara yang harus di uji kebenarannya. Namun, penelitian yang penulis gunakan dengan kajian pustaka (library research) ini, maka penulis menggunakan tekhnik analisa data kajian isi (countent analysis).

\footnotetext{
h. 143

${ }^{3}$ S. Nasotion, Metode Research Penelitian Ilmiah, (Jakarta: Bumi Aksara, 2002), Cet. 5,

4 Riduwan, Skala Pengukuran Variabel-Variabel Penelitian, (Bandung: Alfabeta, 2013), Cet. Ke-10, h. 24

${ }^{5}$ Ibid., h. 31

${ }^{6}$ Riduan, Belajar Mudah Penelitian Untuk Guru, Karyawan Dan Peneliti Pemula, (Bandung: Alfabeta, 2015). h. 12
} 
Kajian ini adalah kajian yang menanfaatkan buku atau dokumen untuk menarik kesimpulan, baik kajian isi yang bersifat deduktif maupun kajian isi yang bersifat induktif. ${ }^{7}$ Pada kajian ini peneliti terlebih dahulu mengadakan survei data untuk memperoleh informasi dari penelitian terdahulu terhadap pengerjaan tanpa memperdulikan apakah data itu primer atau sekunder, di lapangan atau dilaboratorium. Kemudian, menelusuri leteratur yang ada serta mentelaahnya secara tekun. Setelah itu, peneliti mengungkapkan buah pikiran secara kritis dan analistis. ${ }^{8}$

\section{PEMBAHASAN}

Syekh Abdul Qadir Al-Jailani dilahirkan di jilan, sebuah distril tersendiri yang terletak di ujung negeri kuno Thobaristan pada tahun $471 \mathrm{H}$ atau $1078 \mathrm{M} .{ }^{9}$ Beliau lahir pada hari pertama bulan ramadhan yang ditandai dengan tidak mau menyusu pada ibunya disaat siang hari bulan ramadhan, hal ini terjadi karena pertolongan Allah. ${ }^{10}$ Syekh Abdul Qadir Al-Jailani adalah putra dari Abu Sholeh bin Musa bin Abdullah bin Yahya Al-Yazid bin Muhammad bin daud bin musa al-juwainy bin Abdullah al-Makhdli bin Hasan Al-Mutsanna bin Hasan bin Ali bin Abi Thalib ra dan Ibunya bernama Syarifah Fatimah binti Abdullah AlShoma'I bin Abu Jamaluddin bin Mahmud bin Thohir bin Abu Atho Abdillah bin Kamaluddin Isa bin Alauddin Muhammad Al-Jawwad bin Ali Al-Ridha bin Musa Kadzim bin Ja'far As-Shadiq bin Muhammad Al-Baqir bin Zainal Abiding bin Husain Al-Syahid binti Fatimah ra binti Rasulullah SAW. ${ }^{11}$ Syekh Abdul Qadir Al-Jailani menikahi empat orang perempuan dan dari pernikahannya itu dikaruniai empat puluh Sembilan orang anak, yang terdiri dari dua puluh orang laki-laki dan dua puluh Sembilan perempuan.

${ }^{7}$ Lexy J. Moleong, Metodologi Penelitian Kualitatif (Bandung:Remaja Rosdakarya, 2013), Cet. 31, h. 220

${ }^{8}$ Moh. Nazir, Metode Penelitian, (Bogor Selatan: Ghalia Indonesia, 2005), h. 93

${ }^{9}$ Muhammad Thom Afandi, Manaqib Syekh Abdul Qadir Al-Jailani Terjemah Al-Lujain Ad-Daani, Balong Jeruk Kunjang Kediri: Tetes Publishing, 2015), h. 11

${ }^{10}$ Syaikh Abi Danif Al-Baghadadi, Keagungan Syaikh Abdul Qadir Al-Jailani, (JlopoTebel-Bareng-Jombang: Darul-Hikmah, 2009), h. 14

${ }^{11}$ M.J. Ja'far S.Hum, Wasiat Dan Nasehat Syeikh Abdul Qadir Al-Jailani, (Yogyakarta: Lafal, 2014), h. 9 


\section{Guru-guru Syekh Abdul Qadir Al-Jailani}

1. Dalam bidang hadits Syekh Abdul Qadir Al-Jailani berguru kepada:

a. Abu Muhammad Ja'far Bin Ahmad Bin Al-Hasan Bin Ahmad Al-Baghdadi As-Sarraj Al-Qari’ Al-Adib

b. Abu Ghalib Muhammad Bin Al-Hasan Bin Ahmad Al-Hasan Bin Khadzadadza Al-Balaqani

c. Syekh Ash-Shaduq Abu Sa'd Muhammad Bin Abdul Karim Bin Khusyaysy Al-Baghdadi

d. Syekh Abu Bakar Ahmad Bin Al-Muzhaffar Bin Husein Bin Abdullah Bin Susan At-Tammar

e. Syekh Abu Al-Qasim Ali Bin Ahmad Bin Muhammad Bin Bayan Bin ArRazzaz Al-Baghdadi

f. Syekh Abu Thalib Abdul Qadir Bin Muhammad Bin Abdul Qadir Bin Muhammad Bin Yusuf Al-Baghdadi Al-Yusufi

g. Syekh Abu Al-Barakat Hibatullah Bin Al-Mubarak Bin Musa Al-Baghdadi As-Saqathi

h. Syekh Abu Al-Izz Muhammad Bin Al-Mukhtar Bin Muhammad bin abdul wahid bin Abdullah bin al-mua'ayyad billah al-hasyimi al-abbasi

2. Dalam bidang fiqih Syekh Abdul Qadir Al-Jailani berguru kepada:
a. Abul Sa'ad Al Muharrimi
b. Syekh Ali Abu Al-Wafa Bin Aqil
c. Syekh Abi Al-Khattab Al-Kalwadzani Mahfudz Bin Ahmad Al-Jalil
d. Syekh Abu Sa'd Al-Mubarak Bin Al-Mukharrimi Al-Baghdadi
e. Syekh Abu Al-Wafa' Ali Bin Aqil Bin Muhammad Bin Aqil Bin Abdullah Al-Baghdadi Azh-Zhafari
f. Syekh Abu Al-Khattab Mahfuzh Bin Ahmad Bin Hasan Bin Hasan Al-Iraqi Al-Kalwadzaniw

3. Dalam bidang bahasa dan sastra Syekh Abdul Qadir Al-Jailani berguru kepada:
a. Abu Zakarya Ibn Ali Al-Tibrizi
b. Abi Husain Muhammad Bin Qadhi Abu Sa'id Al-Mubarok Bin Ali Al- Mukharrimi


4. Dalam Bidang Tasawuf Syekh Abdul Qadir Al-Jailani Berguru Kepada:
a. Syekh Hammad Al-Dabbas
b. Al-Qadi Abu Said Al Mukharrimi
c. Syekh Zakariyya Yahya Bin Ali
d. Syekh Abi Al-Khair Muhammad Bin Muslim Al-Dabbasa

5. Dalam bidang tahfizh Syekh Abdul Qadir Al-Jailani berguru kepada:
a. Syekh Ali Abual-Wafa Al-Qail

6. Dalam bidang akhlak Syekh Abdul Qadir Al-Jailani berguru kepada:
a. Abi Zakariya Yahya Ibn 'Ali At-Tibrizi
b. Qadli Abi Sa'id Ibn Al-Mubarak
c. Ibnu Aqil
d. Abul Khatthat
e. Abul Husein Al Farra'
f. Al-Qadhi Abu Sa'id Al-Makhrami

\section{Karya Syekh Abdul Qadir Al-Jailani}

1. Al-Ghunyah Li Thaalibil Haqq, tentang fikih.

2. Al-Fath Al-Rabbani Wal Faidhur Rahmaaniy

3. Futuuhul Ghaib

4. Sirrul Asraar Fit-Tashawwuf Ma Yahtaju Ilayhi Al-Arbar

5. Al-Mawahib Al-Rahmaniyya Wa Al-Futuuh Al-Rabbaniyya Fi Maratib AlAkhlaq Al-Sawiyya Wa Al-Maqamat Al-Irfaniyyat

6. Djala' Al-Khatir

7. Yawakit Al-Hikam

8. Malfudzat-I Jalai

9. Syarh-I Ghautsaiya Va Ghayra

10. Khamsata 'Asyara Maktuban

11. Al-Fuydhat Al-Rabbaniyah

12. Bahjat Al-Asrar

13. Al-Fuyudhat Al-Rabbaniyyah Fi Al-Aurad Al-Qadariyyah

14. Hizb Basher Al-Khayrat. ${ }^{12}$

\section{${ }^{12} \mathrm{Ibid}, \mathrm{h} 18$}




\section{Gambaran Ma'rifah Secara Umum}

\section{Ma'rifah}

Istilah ma'rifah berasal dari kata "Al-Ma'rifah", yang berarti mengetahui atau mengenal sesuatu. Menurut Dr. Mustafa Zahri bahwa Ma'rifah adalah ketetapan hati dalam mempercayai hadirnya wujud yang wajib adanya Allah yang menggambarkan segala kesempurnaannya. ${ }^{13}$

Menurut Imam Al-Ghazali, ma'rifat adalah pengetahuan yang tidak menerima keraguan terhadap dzat dan sifat Allah. Ma'rifat terhadap dzat Allah swt adalah mengetahui bahwa sesungguhnya Allah adalah wujud Esa, Tunggal, dan seseuatu Yang Maha Agung, mandiri dengan sendiri-Nya dan tidak ada sesuatu pun yang menyamai-Nya.

Sedangkan ma'rifat kepada sifat adalah mengetahui dengan sesungguhnya bahwa Allah itu Maha Hidup, Maha Mengetahui, Maha Kuasa, Maha Mendengar, Maha Melihat dengan segala sifat keparipurnaan-Nya. Jadi, ma'rifah adalah mengetahui akan rahasia-rahasia Allah dan mengetahui peraturan-peraturan tentang segala yang ada. Selain itu, pendapat al-ghazali diperjelas dengan pendapat lain yang mengatakan bahwa ma'rifat adalah memandang wajah Allah yaitu seseorang yang tatkala dia mencapai tahapan tidak menemukan dalam kalbunya sedikitpun ruang bagi selain Tuhannya.

Ada pula yang mengatakan bahwa hakikat ma'rifat adalah cahaya yang dikaruniakan di dalam kalbu mukmin, dan tiada yang lebih mulia dalam khazanah kecuali ma'rifat. sedangkan tanda-tanda ma'rifa adalah hidupnya kalbu bersama Allah SWT, sebagaimana firman Allah SWT dalam surah anNajm ayat 11

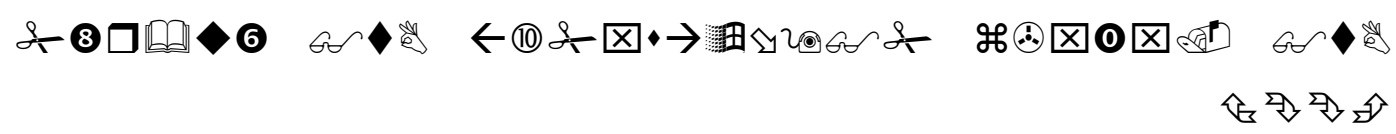

\section{Artinya:Hatinya tidak mendustakan apa yang telah dilihatnya}

Ayat di atas menjelaskan tentang kejujuran, perkataan yang benar. Benar adalah kejujuran bagi setiap hamba, artinya takwa. Orang yang bertakwa itu artinya orang yang sa'i yaitu orang yang bersih, itu dimanakan orang yang berilmu. Orang yang melihat sifat-sifat Allah SWT di dunia ini akan melihat

${ }^{13}$ A. Mustafa, Akhlak Tasawuf, (Bandung: Pustaka Setia, 2010), h. 251 
Zat-Nya kelak di akhirat tanpa perlu ditanyakan dengan cara apa dan bagaimana ia melihat-Nya. Adapun pernyataan-pernyataan yang muncul dari para wali tentang hal melihat diri-Nya seperti ucapan Umar bin al-Khattab "Hatiku melihat Rabbku” yakni dengan cahaya Rabb yang tidak aku lihat", semua itu merupakan penyaksian mereka terhadap sifat-sifat-Nya. sebagaimana firman Allah SWT dalam surah an-Nur ayat 35

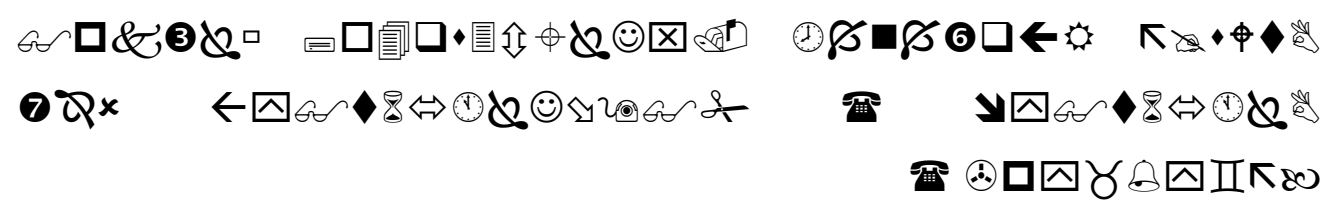

Artinya:Perumpamaan cahaya Allah, adalah seperti sebuah lubang yang tak tembus[1039], yang di dalamnya ada pelita besar. pelita itu di dalam kaca.

Ayat di atas menjelaskan tentang zahir tuhan itu yang diisbatkan melalui musyahadah Muhammad seperti pandangan, pengrasa, dan penglihatan. Maksudnya pandanglah melalui mata batin seperti rasa, akal dan jiwa yang disebut dengan mata hati yang dinamakan kebesaran Allah SWT. Syeikh Abdul Qadir Al-Jailani mengolah dirinya dengan penuh keseriusan, selalu siap sedia utuk bersungguh-sungguh, menjauhi keinginan-keinginan untuk memenuhi kebutuhan dan hajat serta keinginan untuk meminta bantuan orang lain dan sampai dengan usianya 25 tahun berkelana di guru dan tempat-tempat sunyi di irak. Syeikh Abdul Qadir Al-Jailani tidak mengenal manusia dan manusia tidak mengenalnya. Dipermulaan perjalanan suluk, Syeikh Abdul Qadir Al-Jailani mengalami penderitaan oleh cacian, godaan dan segala macam kekhawatiran serta tidak ada setiap ujian kecuali beliau lulus menundukkannya.

Selama berkelana, Syeikh Abdul Qadir Al-Jailani selalu menempati di tempat yang sunyi dan kosong. Yang ia pakai hanyalah jubah bulu yang biasa dikenakan oleh para sufi dan seutas kain menutup bagian kepalanya. Syeikh Abdul Qadir Al-Jailani berjalan tanpa terompah menyusuri jalanan berduri dan jalanan terjal. Sedangkan yang jadi makanannya adalah buah pepohonan, 
sayur-sayuran yang sudah dibuang serta rerumputan yang tumbuh di sekitar sungai. Tidak tidur dan tidak minum air kecuali sedikit. ${ }^{14}$

\section{Ciri-ciri Ahli Ma'rifah}

a. Hatinya bagaikan cermin yang dapat terlihat di dalamnya hal-hal yang ghaib daripada selainnya Dia dan sinar hatinya tiada lain kecuali nurul iman dan nurul yaqin.

b. Dengan kekuatan iman, maka hatinya dapatlah ia bermusyahadah dengan Allah swt dan atas kadar kekuatan Musyahadah, maka dapatlah ia berMarifatullah dengan Asmaullah, Sifatullah.

c. Atas dasar Marifatullah, Asmaullah, Sifatullah maka dapatlah ia mencapai Marifatullah Zatullah yang Maha Agung.

d. Atas dasar kekuatan Marifatullah Zatullah, maka sang hamba mencapai sebagai Insanul Kamil/sifat sempurna.

e. Atas kadar kekuatan sifat sempurnanya, maka ia tenggelamlah ke dalam sifat kesempurnaan Allah karena pengabdiannya sebagai hamba Allah. ${ }^{15}$

f. Selalu memancar cahaya ma'rifah padanya dalam segala sikap dan perilakunya, karena itu sikap wara' selalu ada pada dirinya.

g. Tidak menjadikan keputusan pada sesuatu yang berdasarkan fakta yang bersifat nyata, karena hal-hal nyata menurut ajaran tasawuf belum tentu benar.

h. Tidak menginginkan nikmat Allah yang banyak buat dirinya, karena hal itu bisa membawanya kepada perbuatan yang haram. ${ }^{16}$

\section{Jalan Ma'rifah}

a. Qalbu berfungsi untuk dapat mengetahui sifat Tuhan.

b. Ruh berfungsi untuk dapat mencintai Tuhan.

c. Sir berfungsi untuk melihat Tuhan.

\footnotetext{
${ }^{14}$ Muhammad Thom Afandi, Manaqib Syekh Abdul Qadir Al-Jailani, (Kadiri: Tetes Publishing, 2015), h. 9

${ }^{15}$ Mustafa Zahri, Kunci Memahami Ilmu Tasawuf, (Surabaya: PT Ilmu Bina, 1997), h. 226

${ }^{16}$ A. Mustafa, Op. Cit., h. 252
} 


\section{Maqam Untuk Mencapai Ma'rifah}

orang yang dapat mencapai ma'rifah harus melalui perjalanan spritualnya yaitu harus berniat dengan memurnikan keimanannya, melakukan taubat nasuha, melakukan zuhud dan melakukan ibadah secara terus menerus, baik ibadah lahir maupun ibadah batin. Ibadah batin harus diperkuat dengan empat macam sikap dan perilaku, yaitu:

1. Mengurangi perkataan

2. Mengurangi makan

3. Mengurangi tidur

4. Mengisolir diri

Adapun tingkatan maqam untuk mencapai ma'rifah kepada Allah, yaitu:

1. Dhikir yaitu melalui sejumlah bilangan. dhikir adalah mengucap kalimat tahlil, tahmid, tasbih, istiqfaar, asmaa'u al-husna, membaca ayat-ayat al-qur'an dan berselawat kepada Rasulullah SAW dengan tujuan menenggelamkan pikiran dan perasaan keduniaan, lalu menimbulkan pikiran dan perasaan keakheratan.

2. Tafakur yaitu renungan yang panjang. tafakur adalah renungan hamba terhadap ciptaan, asma' dan sifat Allah yang bertujuan untuk menghadirkan hati mengenai sifat dunia yang baharun dan sifat akherat yang kekal.

3. Al-sukru yaitu hilangnya kesadaran kemanusiaan.

4. Fana' dan baqa' yaitu munculnya kesadaran mistik. fana' diartikan sebagai kebodohan (ketidaktahuan), lalu timbul baqa' yang berarti sikap-tahuan. Fana' maksiat, lalu timbul baqa' ketaatan. Fana' kelalaian, lalu timbul baqa' ingat kepada Allah. Fana sifat-sifat buruk, lalu timbul baqa' sifat-sifat baik. Ma'rifat yang diperoleh dari hasil fana dan baqa meliputi beberapa tingkatan, yaitu:

a. Ma'rifat dengan ciptaan Allah didapat dengan fana ciptaan Allah.

b. Ma'rifat dengan nama Allah didapat dengan fana nama Allah.

c. Ma'rifat dengan sifat Allah didapat dengan fana sifat Allah.

d. Ma'rifat dengan zat Allah didapat dengan fana zat Allah.

5. Muhaadarah yaitu menghadirkan hati nurani dalam kekuasaan Allah SWT

6. Mukasyafah yaitu tersingkapnya tabir pemisah antara hamba dengan tuhannya 
7. Mushaahadah yaitu tercapainya kesaksian hamba dengan Tuhan-Nya. ${ }^{17}$

\section{Konsep Ma'rifat Syeikh Abdul Qadir Al-Jailani}

Syeikh Abdul Qadir Al-Jailani adalah ulama dan imam dalam ilmu-ilmu agama, kalam, dan fikih, serta tokoh terkemuka mazhab Syafi'i dan Hanbali. keberadaannya memberi manfaat yang sangat besar bagi semua orang. Do'a dan kutukannya selalu dikabulkan. Syeikh Abdul Qadir Al-Jailani adalah manusia sempurna yang selalu mengingat Allah, bertafakur, merenung, serta belajar dan mengajar. Hatinya lembut, perilakunya santun, dan parasnya senantiasa tampak ceria.

Syeikh Abdul Qadir Al-Jailani juga selalu bersimpati dan memelihara perilaku yang mulia. dimata orang, Syeikh Abdul Qadir Al-Jailani tampil sebagai sosok yang berwibawa, dermawan, dan gemar member bantuan, nasihat, maupun ilmu. Selain itu, beliau juga menyayangi sesama, terutama kaum mukmin yang taat dan selalu beribadah kepada Allah. Penampilannya selalu terjaga sehingga terlihat tampan, beliau tidak suka ngomong berlebihan. Jika berbicara, meski cepat tetapi setap kata maupun suku katanya terdengar jelas. Bicaranya santun dan yang diucapkannya hanyalah kebenaran. Syeikh Abdul Qadir Al-Jailani menyampaikan kebenaran dengan lantang dan tegas. Beliau tidak peduli apakah kata orang lain akan memuji, mencela, mengeritik, atau bahkan memakinya.

Syeikh Abdul Qadir Al-Jailani senantiasa menerapkan akhlak mulia dan sifat-sifat yang utama dalam setiap dakwahnya kepada manusia, sebagaimana dikatakan bahwa seorang guru rohani tidak akan menjadi guru sejati kecuali jika ia memiliki dua belas macam sifat. Dua sifat diantaranya adalah menyembunyikan aib manusia dan seluruh makhluk, tidak hanya dari orang lain, tetapi juga dari dirinya sendiri dan bersedia memaafkan kesalahan yang paling berat sekalipun. Selain itu, ada dua sifat yang diwariskan dari Nabi Muhammad saw yaitu cinta dan kelembutan. Dari Abu Bakar ra. yaitu mewarisi kejujuran, keikhlasan, kesetiaan, dan kedermawanan. Dari Umar ra. yaitu mewarisi keadilan dan amal makruf nahi munkar. Dari Usman ra, ia mewarisi tawaduk dan kebiasaan shalat di

${ }^{17}$ Mahjuddin, Akhlak Tasawuf 1 Mu'jizat Nabi Karamah Wali Dan Ma'rifat Sufi, (Jakarta: Kalam Mulia, 2009), h. 222 
tengah malam ketika orang-orang tertidur lelap. Sedangkan dari Ali ra, ia mewarisi ilmu dan keberanian.

Syeikh Abdul Qadir Al-Jailani telah berhasil menaklukkan nafsunya dan menjadi manusia sempurna, berkat ilham dan perintah dari Nabi Muhammad saw, Syeikh Abdul Qadir Al-Jailani menjadi guru yang punya hubungan kuat dengan manusia dan beliau juga telah menyerahkan dirinya kepada Allah. Malam yang dilaluinya digunakan untuk tahajud dan tafakur, dan siang beliau gunakan untuk mengabdikan diri kepada umat manusia. Beliau berceramah dalam tiga kali seminggu dihadapan ribuan orang serta setiap pagi dan sore ia habiskan dengan mengajar tafsir, hadis, tauhid, fikih, dan tasawuf. Setelah shalat Zuhur beliau isi dengan memberi nasehat kepada umat, baik pengemis maupun raja. Sebelum magrib, ia gunakan untuk menelusuri jalan-jalan untuk membagikan roti kepada kaum fakir yang disebabkan berpuasa sepanjang tahun. ${ }^{18}$

Syeikh Abdul Qadir Al-Jailani menjelaskan dalam konsep ma'rifat bahwa ma'rifat berasal dari kata arafa, ya'rifu, irfan, ma'rifah yang berarti pengetahuan atau pengalaman. Sedangkan menurut istilah ma'rifat yang berarti pengetahuan tentang rahasia hakikat agama, yaitu ilmu yang lebih tinggi daripada ilmu yang biasa didapati oleh orang-orang pada umumnya. Jadi, ma'rifat adalah pengetahuan yang objeknya bukan pada hal-hal yang bersifat zahir, tetapi lebih mendalam terhadap batinnyadengan mengetahui rahasianya. Hal ini didasarkan pada pandangan bahwa akal manusia sanggup mengetahui hakikat ketuhanan, dan hakika itu satu, dan segala yang maujud berasal dari yang satu. Hakikat ma'rifat adalah cahaya yang dikaruniakan di dalam kalbu mukmin. Sebagaimana dikatakan dalam firman Allah "Hidupnya kalbu dalam musyahadah kepada-ku". Musyahadah yang berarti penyaksian kepada yang haq tanpa perantara, tanpa bagaimana dan tanpa serupa.

Ma'rifat juga merupakan ilmu pengetahuan yang tidak menerima keraguan terhadap dzat dan sifat Allah. Ma'rifat terhadap dzat Allah adalah mengetahui bahwa sesungguhnya Allah adalah wujud Esa, Tunggal dan sesuatu Yang Maha Agung, mandiri dengan sendiri-Nya dan tidak ada sesuatu pun yang menyamaiNya. Sedangkan ma'rifat terhadap sifat Allah adalah mengetahui dengan

${ }^{18}$ Syekh Abdul Qadir Al-Jailani, Biografi Sultan Para Wali, (Jakarta: Zaman, 2015), h. 71 
sesungguhnya bahwa Allah Maha hidup, Maha mengetahui, Maha kuasa, Maha mendengar, Maha melihat dengan segala sifat keparipurnaan-Nya. Jadi, tandatanda ma'rifat adalah hidupnya kalbu bersama Allah SWT.

\section{Pemikiran Syekh Abdul Qadir Al-Jailani Terhadap Pendidikan Ma'rifat Kepada Allah SWT}

Sebagaimana telah dijelaskan dalam bab sebelumnya bahwa Pendidikan ma'rifat menurut syekh Abdul Qadir Al-Jailani yaitu pengetahuan tentang rahasia hakikat agama yang merupakan ilmu pengetahuan yang objeknya bukan pada halhal yang bersifat zahir, tetapi lebih mendalam terhadap batinnya dengan mengetahui rahasianya. Tanda-tanda ma'rifah adalah hidupnya kalbu bersama Allah SWT. Barangsiapa yang sudah hilang keinginan untuk mencapai ilmu yang sedemikian tinggi itu, maka orang itu adalah ibarat orang yang habis seleranya untuk memakan makanan yang baik-baik ataupun seperti orang yang lebih suka memakan tanah daripada memakan roti. Semua selera tubuh kasar ini hilang apabila mati (bercerai nyawa dengan tubuh). Tetapi Ruh tidak mati dan ia tetap membawa ilmu tentang ketuhanan yang ada padanya, bahkan menambah ilmu itu lagi.

Pendidikan ma'rifah timbul dari kajian dan pemikiran kita tentang tubuh kita sendiri, yang membukakan kekuatan, kebijaksanaan dan cinta kepada Allah, Tuhan yang menciptakan segalanya. Kekuasaan-Nya menunjukkan betapa setitik air dijadikan-Nya manusia yang cukup lengkap dan sempurna. KebijaksanaanNya ditunjukkan dengan betapa rumit dan sulitnya anggota-anggota tubuh kita dan saling bersesuaian antara bagian-bagian anggota tubuh yang satu kepada anggota tubuh yang lainnya. Cinta-Nya ditunjukkan dengan kurnia-Nya kepada kita bukan saja anggota-anggota yang paling penting untuk hidup seperti jantung, hati, otak, tetapi juga anggota-anggota tubuh yang tidak paling penting seperti tangan, kaki, lidah dan mata. Kemudian ditambah pula dengan perhiasan seperti hitam rambut, merahnya bibir, bulu mata yang melentik dan sebagai-Nya.

Orang yang mengenal Allah SWT lebih penting dari mengenal tubuh dan tugas-tugas-Nya. Tubuh diibaratkan kuda tunggangan dan Ruh itu ibarat penunggangnya. Tubuh itu dijadikan untuk Ruh dan Ruh itu untuk tubuh. Jika 
seseorang itu tidak tahu dengan dirinya, maka bagaiman ia bisa dekat dengan Allah SWT. Keagungan seorang manusia terletak pada usaha untuk menuju yang abadi, jika tidak maka di dalam dunia yang fana ini manusia itulah yang paling lemah dari segala makhluk karena tunduk kepada lapar, dahaga, panas, sejuk dan duka cita. Hal yang paling disukai akan memberikan bahaya dan hal yang memberi faedah hanya dapat diperoleh melalui usaha dan susah payah.

Tujuan diciptakan-Nya manusia kedunia ini adalah untuk beribadah kepada Allah SWT sebagaimana dijelaskan dalam firman Allah SWT dalam Al-Qur'an surah Adz-Dzaariyat ayat 56:

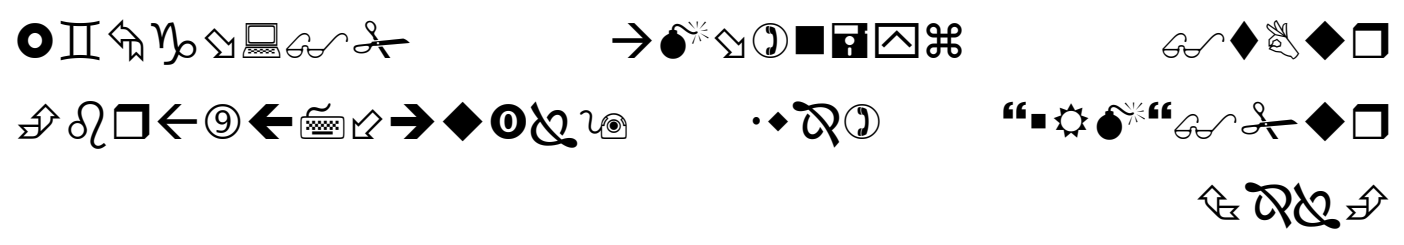

Artinya:dan aku tidak menciptakan jin dan manusia melainkan supaya mereka mengabdi kepada-Ku.

Dan surah Al-Baqarah ayat 21:

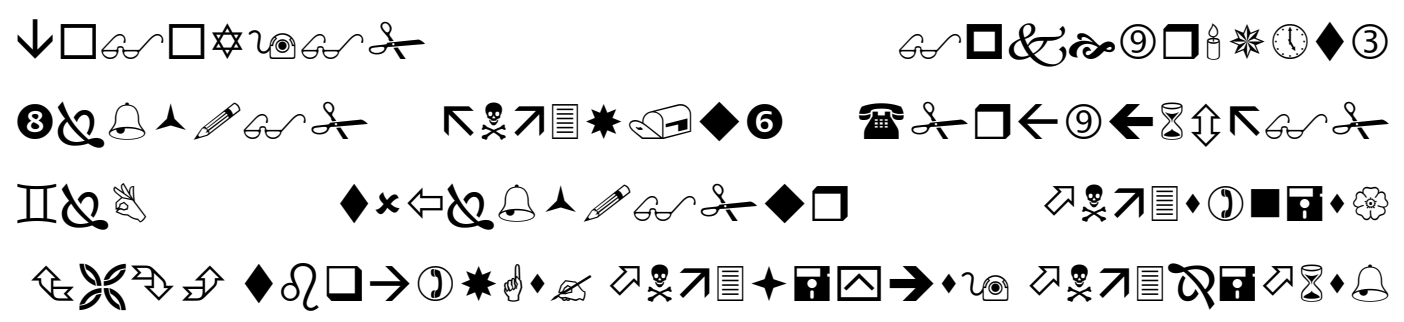

Artinya:Hai manusia, sembahlah Tuhanmu yang telah menciptakanmu dan orang-orang yang sebelummu, agar kamu bertakwa.

Dari ayat di atas menjelaskan bahwa manusia harus menyembah Tuhan yang menciptakannya, segabaimana perkataan Syekh Abdul Qadir Al-Ajailani mengingatkan kita untuk terus belajar mendekatkan diri kepada Allah SWT dengan zuhud terhadap dunia dan segala isinya. Sebab, dunia tidak ada artinya untuk manusia dan tidak ada yang sia-sia bagi orang yang mau belajar untuk menjadi lebih baik, Karena sesungguhnya Allah senantiasa menghargai setiap usaha manusia.

Syekh Abdul Qadir Al-Jailani hidupnya dengan beribadah kepada Allah SWT, semua ilmunya menjadi pembersih kotoran, pendekatannya kepada Allah SWT menguatkan kewaliannya, ingat kepada Allah SWT dengan menghadirkan 
hati menjadi gudangnya, ma'rifah kepada Allah SWT menjadi bentengnya, munajatnya kepada Allah menjadi amal perbuatannya, kewaspadaannya sebagai penghubung dirinya kepada Allah SWT, lapang dada menjadi kecintaannya, kebenaran menjadi lambang hidupnya, terbukanya hati menjadi wataknya, dzikir kepada Allah SWT menjadi ucapannya, persaksiannya kepada Allah SWT menjadi obat, peraturan agama menjadi jembatannya, semua sifat-sifat hakikat menjadi kepribadiannya, menyerah dan puas atas ketentuan Allah SWT, beliau adalah orang yang sangat menyadari akan kejadiannya sebagai hamba Allah SWT dengan secara rutin beribadah kepada Allah SWT, bukan untuk sesuatu dan tidak karena sesuatu melainkan ibadahnya ikhlas karena sebagai hamba yang setia kepada sifat-sifat kesempurnaan Allah SWT. Bahkan Syekh Abdul Qadir AlJailani berkelana terlebih selama 25 tahun barulah beliau melayani masyarakat.

Syekh Abdul Qadir Al-Jailani selalu mengingatkan muridnya untuk terus mengingat Allah SWT, tunduk dan patuh kepada Allah SWT, menyampaikan keperluan kepada Allah SWT, berpikirlah perbuatan baik itu karena karunia dari Allah SWT, anggaplah diri kita tidak berdaya untuk berbuat amal baik apapun. Selain itu, Syekh Abdul Qadir Al-Jailani meminta manusia untuk menutup rapatrapat pintu makhluk dan membuka lebar-lebar pintu hati kita dan Allah SWT. Mengakui semua perbuatan buruk di hadapan Allah SWT, memohon ampuan atas semua kesalahan dan kekurangan amal ibadah kita, yakinlah bahwa tak ada yang dapat memberi mudharat, tak ada yang dapat memberi manfaat, tak ada yang dapat memberi, tak ada yang dapat mencegah kecuali Allah SWT.

\section{KESIMPULAN}

Ma'rifah adalah ketetapan hati dalam mempercayai hadirnya wujud yang wajib adanya Allah yang menggambarkan segala kesempurnaannya. Sedangkan ma'rifat terhadap sifat Allah adalah mengetahui dengan sesungguhnya bahwa Allah Maha hidup, Maha mengetahui, Maha kuasa, Maha mendengar, Maha melihat dengan segala sifat keparipurnaan-Nya. Jadi, tanda-tanda ma'rifat adalah hidupnya kalbu bersama Allah SWT.

Orang yang dapat mencapai ma'rifah harus melalui perjalanan spritualnya yaitu harus berniat dengan memurnikan keimanannya, melakukan taubat nasuha, 
melakukan zuhud dan melakukan ibadah secara terus menerus, baik ibadah lahir maupun ibadah batin. Ibadah batin harus diperkuat dengan empat macam sikap dan perilaku, yaitu: 1. Mengurangi perkataan, 2. Mengurangi makan, 3. Mengurangi tidur, 4. Mengisolir diri.

Adapun tingkatan maqam untuk mencapai ma'rifah kepada Allah, yaitu:

1. Dhikir yaitu melalui sejumlah bilangan tertentu.

2. Tafakur yaitu renungan yang panjang

3. Al-sukru yaitu hilangnya kesadaran kemanusiaan

4. Fana' dan baqa' yaitu munculnya kesadaran mistik

5. Muhaadarah yaitu menghadirkan hati nurani dalam kekuasaan allah

6. Mukasyafah yaitu tersingkapnya tabir pemisah antara hamba dengan tuhan-nya

7. Mushaahadah yaitu tercapainya kesaksian hamba dengan Tuhan-Nya.

Tanda-tanda ma'rifah sesorang adalah hidupnya kalbu bersama Allah SWT., sudah hilang keinginan untuk mencapai ilmu pengetahuan duniawai, maka orang itu adalah ibarat orang yang habis seleranya untuk memakan makanan yang baik-baik ataupun seperti orang yang lebih suka memakan tanah daripada memakan roti. Semua selera tubuh kasar ini hilang apabila mati (bercerai nyawa dengan tubuh). Tetapi Ruh tidak mati dan ia tetap membawa ilmu tentang ketuhanan yang ada padanya.

Dzikir kepada Allah SWT menjadi obat, peraturan agama menjadi jembatannya, semua sifat-sifat hakikat menjadi kepribadiannya, menyerah dan puas atas ketentuan Allah SWT, beliau adalah orang yang sangat menyadari akan kejadiannya sebagai hamba Allah SWT dengan secara rutin beribadah kepada Allah SWT, bukan untuk sesuatu dan tidak karena sesuatu melainkan ibadahnya ikhlas karena sebagai hamba yang setia kepada sifat-sifat kesempurnaan Allah SWT. Bahkan Syekh Abdul Qadir Al-Jailani berkelana terlebih selama 25 tahun barulah beliau melayani masyarakat.

\section{DAFTAR PUSTAKA}

A. Mustafa, Akhlak Tasawuf, (Bandung: Pustaka Setia, 2010) 
Abudin Nata, Metodologi Studi Islam, (Jakarta:PT Raja Grafindo Persada, 2001)

Lexy J. Moleong, Metodologi Penelitian Kualitatif (Bandung:Remaja Rosdakarya, 2013), Cet. 31

Muhammad Thom Afandi, Manaqib Syekh Abdul Qadir Al-Jailani Terjemah AlLujain Ad-Daani, Balong Jeruk Kunjang Kediri: Tetes Publishing, 2015)

M.J. Ja'far, Wasiat Dan Nasehat Syeikh Abdul Qadir Al-Jailani, (Yogyakarta: Lafal, 2014)

Muhammad Thom Afandi, Manaqib Syekh Abdul Qadir Al-Jailani, (Kadiri: Tetes Publishing, 2015)

Mustafa Zahri, Kunci Memahami Ilmu Tasawuf, (Surabaya: PT Ilmu Bina, 1997)

Moh. Nazir, Metode Penelitian, (Bogor Selatan: Ghalia Indonesia, 2005)

Mahjuddin, Akhlak Tasawuf 1 Mu'jizat Nabi Karamah Wali Dan Ma'rifat Sufi, (Jakarta: Kalam Mulia, 2009)

Riduwan, Skala Pengukuran Variabel-Variabel Penelitian, (Bandung: Alfabeta, 2013), Cet. Ke-10

Riduan, Belajar Mudah Penelitian Untuk Guru, Karyawan Dan Peneliti Pemula, (Bandung: Alfabeta, 2015)

Syaikh Abi Danif Al-Baghadadi, Keagungan Syaikh Abdul Qadir Al-Jailani, (Jlopo-Tebel-Bareng-Jombang:Darul-Hikmah, 2009)

S. Nasotion, Metode Research Penelitian Ilmiah, (Jakarta: Bumi Aksara, 2002), Cet. 5

Syekh Abdul Qadir Al-Jailani, Biografi Sultan Para Wali, (Jakarta: Zaman, 2015)

Zainur Rofiq Ash-Shodiqy, Biografi Syekh Abdul Qadir Al-Jailani, (Jombang: Darul Hikmah, 2014) 